\title{
N-Terminal Acetylation-Targeted N-End Rule Proteolytic System: The Ac/N-End Rule Pathway
}

\author{
Kang-Eun Lee ${ }^{1,2}$, Ji-Eun Heo ${ }^{1,2}$, Jeong-Mok Kim ${ }^{1}$, and Cheol-Sang Hwang ${ }^{1, *}$
}

\begin{abstract}
Although No-terminal acetylation (Nt-acetylation) is a pervasive protein modification in eukaryotes, its general functions in a majority of proteins are poorly understood. In 2010, it was discovered that Nt-acetylation creates a specific protein degradation signal that is targeted by a new class of the $\mathrm{N}$-end rule proteolytic system, called the Ac/Nend rule pathway. Here, we review recent advances in our understanding of the mechanism and biological functions of the $A c / N$-end rule pathway, and its crosstalk with the Arg/N-end rule pathway (the classical $\mathrm{N}$-end rule pathway).
\end{abstract}

\section{INTRODUCTION}

Conditional and constitutive proteolysis are essential life processes. Living cells exploit metabolic turnover to adjust intracellular protein levels, restrict unwanted or aberrant protein accumulation, and supply protein and peptide fragments or free amino acids for physiological needs (Varshavsky, 2011; Zattas and Hochstrasser, 2015). Malfunctions in regulated proteolysis lead to the accumulation of misfolded or abnormal proteins, causing many fatal diseases, including cancers, immunological or neurobiological disorders, as well as aging (Ciechanover and Kwon, 2015; Varshavsky, 2011). Detailed knowledge of intracellular proteolytic machineries and their modes of action will therefore provide new insight into drug interventions for the treatment of devastating maladies or general health maintenance.

The ubiquitin-proteasome system (UPS) is involved in the majority of regulated proteolysis within a cell. The first welldefined protein degradation signals (degrons) in the UPS were $\mathrm{N}$-degrons, which comprise destabilizing Nt-residues. Their detailed examination has revealed the $\mathrm{N}$-end rule, which enables an Nt-residue or its modification to regulate the in vivo halflife of a protein (Varshavsky, 2011). The original (classical) Nend rule pathway (now called the Arg/N-end rule pathway) targets unmodified destabilizing Nt-residues for degradation

${ }^{1}$ Department of Life Sciences, Pohang University of Science and Technology, Pohang, Gyeongbuk 790-784, Korea, ${ }^{2}$ These authors contributed equally to this work.

*Correspondence: cshwang@postech.ac.kr

Received 7 December, 2015; revised 11 January, 2016; accepted 14 January 2016; published online 16 February, 2016

Keywords: degron, $\mathrm{N}$-end rule, $\mathrm{N}$-terminal acetylation, proteolysis, ubiquitin
(Bachmair et al., 1986). In contrast, a new branch of the $\mathrm{N}$-end rule pathway (called the $\mathrm{Ac} / \mathrm{N}$-end rule pathway) recognizes the Nt-acetyl group of cellular proteins for proteolysis (Hwang et al., $2010 b)$. Recent studies on the Ac/N-end rule pathway have revealed a variety of cellular functions, including protein quality and subunit stoichiometry control (Hwang et al., 2010b; Kim and Hwang, 2014; Kim et al., 2014; Shemorry et al., 2013), blood pressure regulation via G-protein signaling (Park et al., 2015), and immune responses to pathogens in plants (Xu et al., 2015). Here, we review current knowledge related to the mechanism and biological functions of the $\mathrm{Ac} / \mathrm{N}$-end rule pathway.

\section{NT-ACETYLATION, MACHINERY, AND FUNCTIONS}

Nascent cellular proteins harbor Nt-methionine (Nt-Met), which is co-translationally removed by ribosome-bound Metaminopeptidases (MetAPs) if small residues (Ala, Gly, Ser, Cys, Thr, Pro, or Val) are positioned at the penultimate site. Nt-Met removal is evolutionarily conserved and occurs in approximately two-thirds of cellular proteins (Giglione et al., 2015). In eukaryotes, both retained Nt-Met and newly exposed Nt-residues (immediately after Nt-Met removal or their proteolytic cleavage) are very frequently $\mathrm{N} \alpha$-terminally acetylated (Nt-acetylated); Nt-acetylation occurs in $80-90 \%$ and $50-70 \%$ of cytosolic human and yeast proteins, respectively (Van Damme et al., 2012). Unlike the reversible $\mathrm{N} \varepsilon$ acetylation/deacetylation, Nt-acetylation appears to be irreversible because no Nt-deacetylases have been identified to date (Starheim et al., 2012). Additionally, Nt-acetylation takes place both cotranslationally and posttranslationally in vivo (Gautschi et al., 2003).

Nt-acetylases catalyze the covalent attachment of an acetyl moiety from acetyl-CoA to the free $\alpha$-amino group of a protein, which alters the steric or chemical properties of the $\mathrm{N}$ terminus of a protein by neutralizing its positive charge and making the Nt-residue larger and more hydrophobic (Aksnes et al., 2015b). Nt-acetylases belong to the GCN5-related Nacetyltransferase (GCNT) family (Polevoda et al., 1999) and are classified as NatA, NatB, NatC, NatD, NatE, and NatF based on substrate specificity and subunit compositions. The substrate specificity of each Nt-acetylase is mostly based on the first two protein residues. Of the $6 \mathrm{Nt}$-acetylases (NatA to F), NatA, NatB, and NatC primarily act on protein N-termini (Aksnes et al., 2015b) (Fig. 1).

NatA consists of a catalytic subunit Naa10 (Ard1) and an auxiliary subunit Naa15 (Nat1) (Mullen et al., 1989; Park and Szostak, 1992), and acetylates Ser, Ala, Cys, Gly, Thr, and Val 

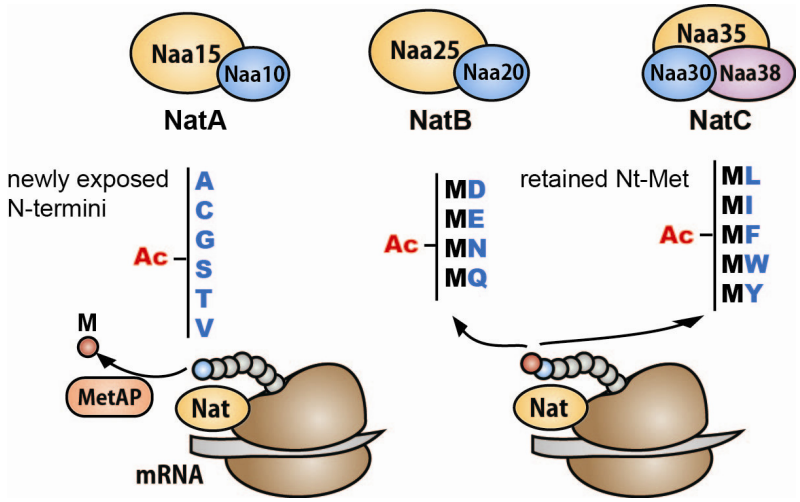

$\mathrm{N}$-termini (Aksnes et al., 2015b) (Fig. 1). NatA functions in cell proliferation, gene silencing, stress resistance, mating process, ribosome biogenesis, apoptosis, protein folding and disaggregation, photosynthesis, development, and stress responses (Aksnes et al., 2015b; Dorfel and Lyon, 2015). Loss of NatA causes a wide range of phenotypes depending on organisms, from slight growth defects to lethality (Aksnes et al., 2015b; Dorfel and Lyon, 2015). In humans, dysregulation of NatA results in various cancer types and neuronal diseases (Kalvik and Arnesen, 2013). In particular, missense or splicing mutations of Naa10, a catalytic subunit of NatA, cause X-linked human genetic disorders, including Ogden Syndrome (Rope et al., 2011) and Lenz microphthalmia syndrome (Esmailpour et al., 2014).

NatB contains a catalytic subunit, Naa20, and an auxiliary subunit, Naa25, and specifically targets N-terminal Met with Asn, Asp, Gln, or Glu at the second position (Fig. 1). NatB plays roles in cell growth in response to various stressors, mitochondrial inheritance, actin cable formation, cell wall maintenance, flowering regulation, plant development, etc. (Aksnes et al., 2015b; Ferrandez-Ayela et al., 2013; Lee et al., 2014).

NatC has a catalytic subunit, Naa30, and two accessory subunits, Naa35/Naa38, and primarily acetylates Nt-Met with bulky hydrophobic residues at position 2 (Fig. 1). It affects cell growth, protein targeting, viral particle maintenance, stress responses, chloroplast development, etc. (Aksnes et al., 2015b; Pesaresi et al., 2003).

NatD, NatE, and NatF include only catalytic subunits Naa40, Naa50, and Naa60, respectively. NatD acetylates solely the Nterminus of histone $\mathrm{H} 2 \mathrm{~A}$ or $\mathrm{H} 4$ and partially regulates histone modification and ribosomal DNA silencing (Polevoda et al., 2009). NatE and NatF display slightly overlapping substrate specificities with NatC. NatE is involved in chromosome segregation and microtubule growth. Interestingly, membranelocalized NatF is only found in multicellular organisms and mainly acetylates cytosolic-faced N-termini of transmembrane proteins, thus maintaining Golgi structural integrity (Aksnes et al., 2015b; 2015c; Van Damme et al., 2011).

The function of $\mathrm{Nt}$-acetylation on a vast number of cellular proteins has remained a conundrum since its discovery (Narita, 1958). However, studies on individual proteins have revealed that $\mathrm{Nt}$-acetylation contributes to protein stability, degradation, interactions, targeting, activity, etc. (Behnia et al., 2004; Forte et al., 2011; Hwang et al., 2010b; Jornvall, 1975; Scott et al., 2011; Setty et al., 2004). Schulman and colleagues have shown that $\mathrm{Nt}$-acetylation of the E2 enzyme Ubc12 increases its binding affinity to the E3 ligase Dcn1 by approximately 100-fold, thereby promoting E3 ligase activity (Scott et al., 2011). In addition, Nt-acetylation affects global protein folding, chaperone
Fig. 1. Substrate specificity and subunit compositions of Ntacetylases. Among $6 \mathrm{Nt}$-acetylases (NatA-F), NatA, NatB, and NatC mainly Nt-acetylate cellular proteins. NatA consists of a catalytic subunit, Naa10, and an auxiliary subunit, Naa15, and acetylates Ser (S), Ala (A), Cys (C), Gly (G), Thr (T), or Val (V) N-termini of its substrates after Nt-Met removal by methionine aminopeptidases (MetAPs). NatB consists of a catalytic subunit, Naa20, and an auxiliary subunit, Naa25, and Nt-acetylates Met-Asn (MN), MetAsp (MD), Met-Gln (MQ), or Met-Glu (ME) on cellular proteins. NatC contains a catalytic subunit, $\mathrm{Naa} 30$, and auxiliary subunits, Naa35 and Naa38, and Nt-acetylates Met-lle (MI), Met-Phe (MF), Met-Trp (MW), Met-Leu (ML), or Met-Tyr (MY) on its substrates.

expression, prion stability, and disaggregation of neurodegenerative proteins, such as $\beta$-amyloid, huntingtin, or $\alpha$-synuclein (Arnesen et al., 2010; Holmes et al., 2014; Pezza et al., 2009). Nt-acetylation also precludes the targeting of cytosolic proteins to the endoplasmic reticulum (ER) (Forte et al., 2011) and transit polypeptide import into plastids (Bischof et al., 2011).

$\mathrm{Nt}$-acetylation has been largely regarded as a metabolic stabilizer that protects proteins or peptides from destruction (Jornvall, 1975). For example, Nt-acetylated globins and lysozymes are more stable than their unacetylated counterparts (Hershko et al., 1984). Nt-acetylation also blocks the Ntubiquitylation-mediated degradation of several cellular proteins, in which a linearly attached Nt-Ub moiety serves as a specific degron (Ciechanover and Ben-Saadon, 2004). Furthermore, $\mathrm{Nt}$-acetylation stabilizes $\mathrm{Arg} / \mathrm{N}$-end rule substrates by directly inhibiting $\mathrm{N}$-degron recognition by the Arg/N-end rule pathway (Varshavsky, 2011) (see below). However, Nt-acetylation also creates a specific degron that is targeted by the $\mathrm{Ac} / \mathrm{N}$-end rule pathway (Hwang et al., 2010a; Varshavsky, 2011).

\section{N-DEGRONS, THE N-END RULE, AND THE ARG/N-END RULE PATHWAY}

Ubiquitin (Ub) is a small 76-amino-acid protein that is highly conserved across all eukaryotes. Ubiquitylation links the carboxyl terminus of Gly in $\mathrm{Ub}$ to the Ne-group of Lys or, relatively rarely, to the N $\alpha$-amino group of Met in cellular proteins. The covalent linkage of $\mathrm{Ub}$ to target substrates requires consecutive reactions of Ub-activating enzymes (E1s), Ub-conjugating enzymes (E2s), and Ub ligases (E3s). The ubiquitylation reaction repeats several times to generate a polyubiquitylated substrate that is selectively eliminated by the $26 \mathrm{~S}$ proteasome. In the UPS, E3 ligase directly contacts target substrates for polyubiquitylation and subsequent proteasomal degradation (Varshavsky, 2011; Zattas and Hochstrasser, 2015). One fundamental question related to the UPS is exactly what structural or sequence features within a target protein trigger its Ubmediated destruction by the $26 \mathrm{~S}$ proteasome; are there any specific degrons (Kim and Hwang, 2014; Ravid and Hochstrasser, 2008)?

Varshavsky and colleagues first defined the primary degrons in the UPS (called N-degrons) based on the unexpected observation that the half-lives of engineered $\beta$-galactosidases with varied $\mathrm{Nt}$-residues are determined by an exposed $\mathrm{Nt}$-residue in Saccharomyces cerevisiae (Bachmair et al., 1986). According to the stability of the resulting $\beta$-galactosidases, they classified Nt-amino acids as either stabilizing or destabilizing residues (Bachmair et al., 1986). N-degrons include primary destabilizing 
A

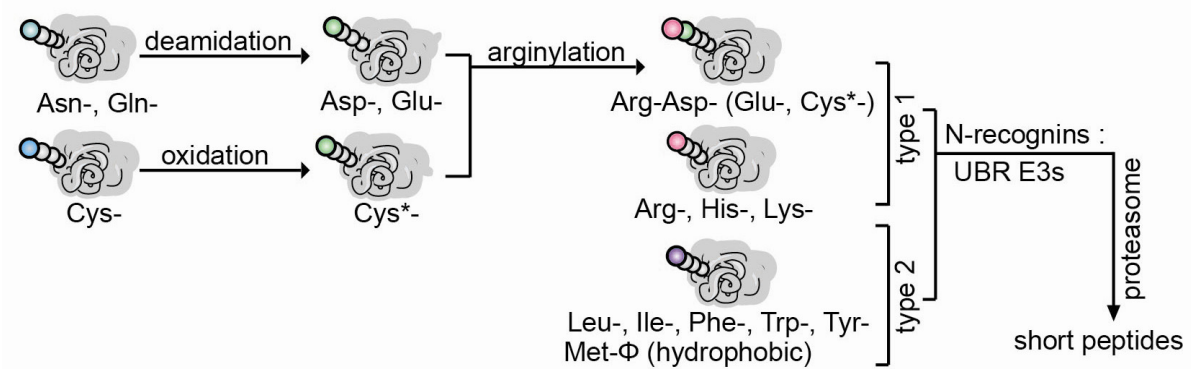

B

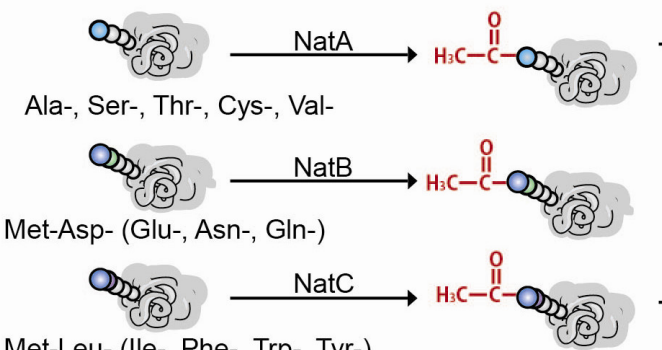

Met-Leu- (Ile-, Phe-, Trp-, Tyr-)

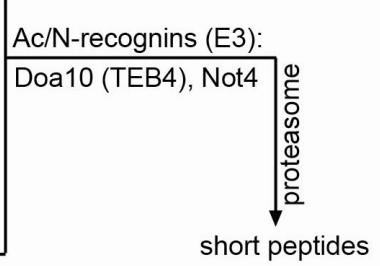

Fig. 2. Two branches of the $\mathrm{N}$-end rule pathways in eukaryotes. (A) The Arg/N-end rule pathway, which targets unmodified Arg, His, Lys, Leu, Ile, Phe, Trp, Tyr, and Met- $\Phi$ (hydrophobic) Nt-residues. Nt-Gln and Asn are destabilizing after Ntdeamidation and subsequent arginylation. Nt-Cys also becomes destabilizing through preliminary oxidation and subsequent $\mathrm{Nt}$ arginylation. (B) The Ac/N-end rule pathway, which targets Ntacetylated residues of cellular proteins for degradation. Doa10 and Not4 are yeast Ac/ $\mathrm{N}$-recognins and Teb4 is a mammalian Ac/Nrecognin. In addition to the NatA, $\mathrm{NatB}$, and NatC substrates, other $\mathrm{Nt}$-acetylated proteins are potentially targeted by the $\mathrm{Ac} / \mathrm{N}$-end rule pathway for degradation.
Nt-residues, internal Lys residue(s) for ubiquitylation, and flexible region(s) for the exposure of substrate Nt-residues. Extensive examination of $\mathrm{N}$-degrons has revealed the $\mathrm{N}$-end rule and the related proteolytic system, called the $\mathrm{N}$-end rule pathway (Tasaki et al., 2012; Varshavsky, 2011).

The $\mathrm{N}$-end rule pathway is generally grouped into the Arg/Nend rule pathway and the Ac/ $\mathrm{N}$-end rule pathway in eukaryotes (Fig. 2). The Arg/N-end rule pathway targets specific unmodified Nt-residues for polyubiquitin-mediated proteolysis by the 26 S proteasome (Varshavsky, 2011) or, to a lesser extent, by autophagy (Cha-Molstad et al., 2015) (Fig. 2A). In eukaryotes, the Arg/N-end rule pathway employs specific UBR-type E3 ligases as N-recognins, which are recognition components of the $\mathrm{N}$-end rule pathway. The UBR-type E3s bind directly to unmodified basic (Arg, Lys, His) and large hydrophobic (Leu, Phe, Tyr, Trp, lle) destabilizing Nt-residues. Nt-Asn and GIn can act as destabilizing residues through their deamination via Ntamidases, resulting in Asp or Glu, and subsequent Ntarginylation via Arg-tRNA-protein transferases (ATEs) (Kwon et al., 1999; Varshavsky, 2011). Nt-Cys also becomes destabilizing through its oxidation by NO, oxygen, or cysteine oxidases, and entails Nt-arginylation by ATEs. Subsequently, Ntarginylated proteins are directly recognized by UBR-type $\mathrm{N}$ recognins for polyubiquitin-mediated degradation by the $26 \mathrm{~S}$ proteasome (Gibbs, 2015; Tasaki et al., 2012; Varshavsky, 2011). In addition to primary destabilizing Nt-residues, the Arg/N-end rule pathway directly recognizes, for proteolysis, NtMet of cellular proteins with a hydrophobic residue at the $2^{\text {nd }}$ position, termed MФ-degrons (Kim et al., 2014) (Fig. 2A).

The functions of the Arg/N-end rule pathway include sensing small molecules (e.g., heme, di/tripeptides, and oxygen), eliminating abnormal proteins, regulating genome stability, apoptosis, DNA repair, G-protein signaling, autophagy, fungal pathogenesis, plant hormone responses, leaf senescence, cardiac signaling, and the viral life cycle (Cha-Molstad et al., 2015; Dougan et al., 2012; Gibbs et al., 2014; Hwang et al., 2010a; Sriram et al., 2011; Tasaki et al., 2012; Varshavsky, 2011). The Arg/N-end rule pathway also mediates the degradation of breast cancerrelated tumor suppressor 1 (BRCA1) (Xu et al., 2012) and the
Parkinson's disease-associated protein PTEN-induced putative kinase 1 (PINK1) (Yamano and Youle, 2013). Interestingly, loss of human UBR1, an E3 ligase of the Arg/N-end rule pathway, causes Johanson-Blizzard Syndrome, which is characterized by physical malformations and pancreatic exocrine insufficiency (Hwang et al., 2011; Zenker et al., 2005).

\section{THE NT-ACETYLATION-TARGETED N-END RULE PATHWAY (THE AC/N-END RULE PATHWAY)}

The Arg/N-end rule pathway classifies Met, Ser, Thr, Val, Cys, Ala, and Pro as stabilizing Nt-residues (Varshavsky, 2011). However, Nt-Cys is readily oxidized in mammalian and plant cells, and subsequently arginylated by ATEs following its targeting to UBR-type N-recognins (Gibbs et al., 2011; Hu et al., 2005; Lee et al., 2005; Weits et al., 2014). Interestingly, reporters with Nt-Cys are apparently long-lived in S. cerevisiae, which does not retain typical NO synthases (Hu et al., 2005), but produces significant amounts of NO or reactive oxygen species (Bhattacharjee et al., 2009). Thus, reporters with Nt-Cys were assumed to be destabilized only if the Nt-Cys could be oxidized which depends on downstream sequence contexts. Indeed, NtCys-reporters bearing non-basic residues at position 2 become destabilized. Additionally, otherwise identical reporters with Met, Ser, Thr, Ala, or Val N-termini are short-lived, in contrast to longlived reporters with Nt-Gly or Pro (Hwang et al., 2010b) (Fig. 2B). The first two Nt-residue-dependence of short-lived reporters implicates likely correlation with the substrate specificity of $S$. cerevisiae Nt-acetylases that act on Met, Ala, Val, Ser, Thr, or Cys N-termini, but very rarely or never on Nt-Gly or Pro, and Ntresidues with basic residues at the penultimate site (Aksnes et al., 2015b). More interestingly, short-lived reporters with nonbasic residues at position 2 do not involve Ubr1, the sole $\mathrm{N}$ recognin of the Arg/N-end rule pathway in S. cerevisiae. Instead, the reporters are dramatically stabilized in the absence of an ER-transmembrane Doa10 E3 ligase, which mediates the degradation of both cytosolic and nuclear or ER proteins in concert with Ubc6/Ubc7 E2s (Hwang et al., 2010b; Swanson et al., 2001) (Fig. 2B). Strikingly, Doa10 preferentially interacts with 
acetylated Nt-Met, Ala, Ser, Cys, Thr, and Val, rather than their non-acetylated counterparts. Furthermore, Doa10 is required for the degradation of not only artificial model substrates, but also some $\mathrm{Nt}$-acetylated native proteins, including MAT $\alpha 2$ (a mating type regulator), Tbf1 (a telomerase regulator), Slk19 (a chromosome segregation regulator), His3 (a histidine biosynthetic enzyme), Hsp104 (a chaperone), Ubp6 (a deubiquitylating enzyme), Aro8 (an aromatic aminotransferase), and Ymr090w (an unknown protein) (Hwang et al., 2010b).

Khemlinskii and Knop showed that the degradation of a CLmCherry-sfGFP fluorescent protein timer with Nt-Cys-Leu, a plausible Ac/N-degron, involves Doa10 E3 ligase and its cognate E2s Ubc6/Ubc7 (Khmelinskii and Knop, 2014). Fields and colleagues also demonstrated that chimeric fusions between Deg1 (1-67 residues of Mat 2 ) and Leu2 are longer-lived when Asn at position 2 is replaced by a basic Lys or Arg (Kim et al., 2013), which suppresses Nt-acetylation in yeast (Arnesen et al., 2009). Additionally, Deg1-Leu2 becomes stabilized in an naa20 $\Delta$ mutant that lacks a catalytic subunit of cognate NatB $\mathrm{Nt-acetylase} \mathrm{(Kim} \mathrm{et} \mathrm{al.,} \mathrm{2013),} \mathrm{similar} \mathrm{to} \mathrm{another} \mathrm{Deg1-Ura3}$ reporter (Hwang et al., 2010a). However, Nt-acetylation slightly perturbs the proteolysis of different versions of Deg1-fusion and endogenous MAT $\alpha 2$ (Zattas et al., 2013).

\section{COMPLEMENTARITY BETWEEN THE ARG/N-END RULE AND THE AC/N-END RULE PATHWAYS}

Features of Nt-acetylation, e.g., its prevalence, cotranslationality, and apparent irreversibility, indicate that most proteins should retain acetylated $\mathrm{N}$-degrons (Ac/ $\mathrm{N}$-degrons) from their emergence from ribosomes to their destruction (Mogk and Bukau, 2010; Varshavsky, 2011). Nonetheless, many cellular proteins bear both acetylated and unacetylated $\mathrm{Nt}$-residues owing to partial Nt-acetylation. Moreover, some cellular proteins are rarely or never Nt-acetylated (Aksnes et al., 2015b). The built-in property of Ac/N-degrons suggests that unacetylated Nt-residues also act as imprinted intrinsic degrons. Hence, we presumed that unacetylated stabilizing Nt-residues of the $\mathrm{Arg} / \mathrm{N}$-end rule pathway might be destabilizing depending upon their downstream sequence contexts, especially the $2^{\text {nd }}$ residues. To test this possibility, we focused on Nt-Met because it is present almost every nascent polypeptide. We found that Nt-Met acts as specific protein degrons if it is followed by hydrophobic residues $(\Phi)$ (Leu, Phe, lle, Trp, Tyr, Gly, or Ala), and these are termed Met- $\Phi$ degrons (Kim et al., 2014). Interestingly, yeast Ubr1 and mouse UBR1 and UBR2 E3 ligases of the Arg/N-end rule pathway bind specifically to Met- $\Phi / \mathrm{N}$-degrons. We also showed that the Arg/N-end rule pathway eliminates, through Met- $\Phi / \mathrm{N}$-degrons, quasi-randomly selected natural Met- $\Phi$ protein Msn4 (a transcription activator), Sry1 (a 3hydroxyaspartate dehydratase), Arl3 (a Golgi-bound GTPase), and Pre5 (a proteasome subunit) as well as misfolded Met- $\Phi$ proteins (Kim et al., 2014). The finding of Met- $\Phi / N$-degrons enormously increases the number of $\mathrm{Arg} / \mathrm{N}$-end rule substrates because more than $15 \%$ of DNA-encoded proteins have NtMet- $\Phi$ sequences in both yeast and humans. Furthermore, detailed analyses of Met- $\Phi$ degrons have unraveled the complementary crosstalk between the Ac/N-end rule and the Arg/Nend rule pathways. For example, when Met- $\Phi$ proteins protrude from ribosomes, the Arg/ $\mathrm{N}$-end rule pathway immediately attacks them for degradation. Otherwise, if Nt-acetylated, the Ac/N-end rule pathway is activated and eliminates Met- $\Phi$ proteins by recognizing their Nt-acetyl moiety. Consequently, the complementary collaboration between the $\mathrm{Arg} / \mathrm{N}$-end rule and
Ac/ $\mathrm{N}$-end rule pathways makes it possible to efficiently eliminate Met- $\Phi$ proteins irrespective of their Nt-acetylation states for physiological needs (Kim and Hwang, 2014; Kim et al., 2014). Furthermore, Nt-acetylation not only precludes the targeting of Met- $\Phi$ proteins by the Arg/N-end rule pathway, but also converts Met- $\Phi / \mathrm{N}$-degrons into AcMet- $\Phi / \mathrm{N}$-degrons, making them susceptible to the Ac/ $\mathrm{N}$-end rule pathway (Kim and Hwang, 2014; Kim et al., 2014).

A combined analysis of bioinformatics and proteomic data has revealed that substantial fractions of proteins $(\sim 10 \%)$ are potentially destroyed by retained Nt-Met (Meinnel et al., 2005). In particular, the transient retention of Nt-Met destabilizes chloroplast D2 variants (Giglione et al., 2003), $\beta$-glucuronidase in plants (Sawant et al., 2001), and a GST variant in S. cerevisiae (Chen et al., 2002). Furthermore, Ubr1 may mediate the degradation of a previously identified Met- $\Phi$-type extension of Ura3 (with Nt-MLDDKCRVTP) via its Nt-Met-Leu sequence (Ghislain et al., 1996). In contrast, treatment with the MetAP2 inhibitor TNP-470 dramatically stabilizes a Rab37 GTPase (with a MetThr Nt sequence) in murine pulmonary endothelial cells, suggesting that the retained Nt-Met of Rab37 also prevents its NatA-mediated Nt-acetylation and subsequent degradation by the Ac/N-end rule pathway (Sundberg et al., 2011). Together, the identification of Nt-Met as an N-degron indicates that virtually all 20 amino acids may serve as potential destabilizing Nt-residues according to their downstream sequence contexts and $\mathrm{Nt}$-acetylation status. For example, fructose-1,6-bisphosphatase, a key regulatory enzyme of gluconeogenesis, is targeted by the GID (glucose-induced degradation-deficient) E3 ligase complex in $S$. cerevisiae. Interestingly, substitutions of the Nt-Pro of fructose-1,6bisphosphatase with other residues abrogate its degradation, suggesting the GID E3 ligase recognizes the Nt-Pro of the metabolic enzyme (Hammerle et al., 1998; Menssen et al., 2012). Additionally, the Drosophila apoptosis inhibitor DIAP1 and DIAP2 E3 ligases directly contact Nt-Ala of processed caspases for proteolysis as plausible specific Ala/N-degron and Ala/N-recognins (Ditzel et al., 2003). Furthermore, the replacement of the penultimate site (Pro-2) in thymidylate synthase with certain amino acids profoundly influences its half-life through Ub-independent proteasomal degradation (Pena et al., 2009), similar to bacteria that contain the Ublacking prokaryotic $\mathrm{N}$-end rule pathway (Dougan et al., 2012). It is unclear which components directly recognize the Nt-Pro of thymidylate synthase for Ub-independent proteolysis.

\section{CONTROL OF SUBUNIT STOICHIOMETRY IN COMPLEXES BY THE AC/N-END RULE PATHWAY}

Although most proteins obtain $\mathrm{Ac} / \mathrm{N}$-degrons during or immediately following their synthesis, the lack of individual Ntacetylases does not significantly affect global protein expression levels, suggesting little correlation between Nt-acetylation and protein stability (Garrels et al., 1997; Helbig et al., 2010). $\mathrm{Ac} / \mathrm{N}$-degrons were, therefore, proposed to be conditionally active depending on the accessibility of $\mathrm{Ac} / \mathrm{N}$-recognins within a polypeptide or a multi-subunit complex (Fig. 3A). For example, if a protein is properly folded or assembled into a cognate complex, the $\mathrm{Ac} / \mathrm{N}$-degron may be protected from the attack by the $\mathrm{Ac} / \mathrm{N}$-end rule pathway. Otherwise, the Ac/N-degrons will remain exposed, leading to their elimination by the Ac/Nend rule pathway (Hwang et al., 2010a; Mogk and Bukau, 2010). The conditionality of built-in Ac/N-degrons plays a pivotal role in the control of protein quality and the adjustment 
$\boldsymbol{A}$

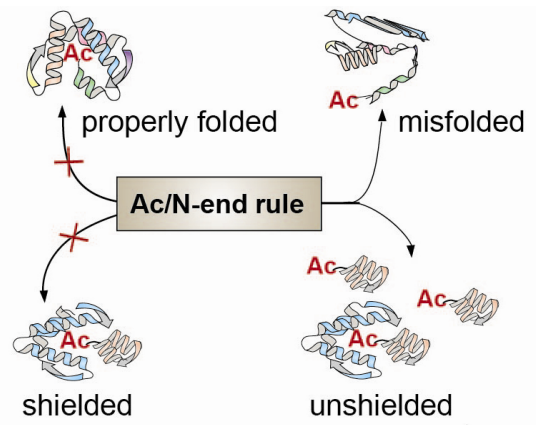

C

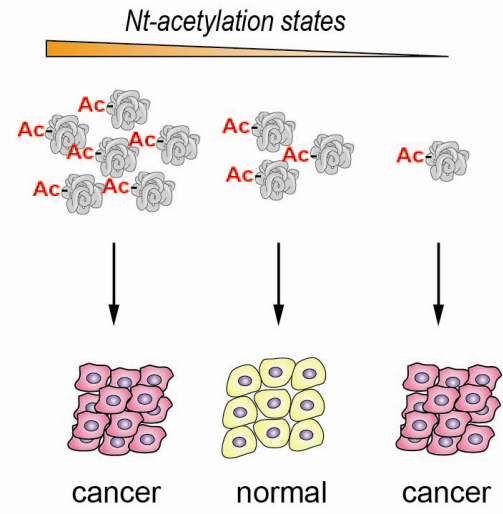

$\boldsymbol{B}$

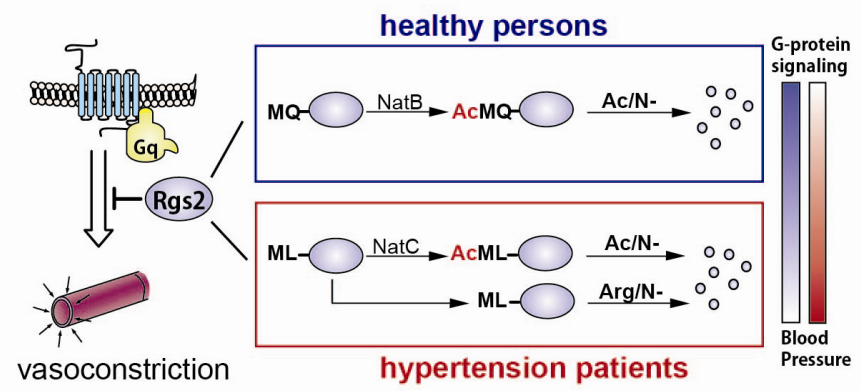

$\boldsymbol{D}$

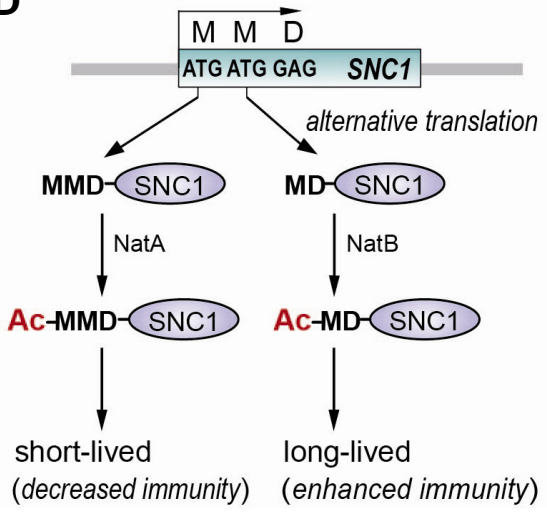

Fig. 3. Functions of the $\mathrm{Ac} / \mathrm{N}$-end rule pathway. (A) Control of protein quality and subunit stoichiometry. The Ac/N-end rule pathway targets misfolded proteins or unassembled subunit(s) of complex proteins with Ac/N-degrons. (B) Regulation of blood pressure via G-protein signaling. The Ac/N-end rule pathway degrades Nt-acetylated wild-type MQ-Rgs2. In contrast, the hypertension-related ML-Rgs2 with a Met- $\Phi$ degron is targeted by either the Ac/N-end rule pathway or the Arg/N-end rule pathway according to its Nt-acetylation status. Dual targeting of ML-Rgs2 by two branches of the $\mathrm{N}$-end rule pathways dramatically decreases Rgs2 levels, and thereby increases blood pressure via augmented Gprotein signaling and subsequent vasoconstriction. (C) Dysregulation of Nt-acetylation most likely affects protein stability, thus causing many cancers. (D) Control of pathogen immunity in plants. Plants contain two SNC1 (suppressors of nod-like protein receptor 1) variants with MetMet-Asp (MMD) or Met-Asp (MD) N-termini owing to alternative translation. NatA Nt-acetylates MMD-SNC1 for degradation, whereas NatB Ntacetylates MD-SNC1 for stabilization. Consequently, the steady-state levels of SNC1 are directly involved in plant immunity.

of subunit stoichiometries of protein complexes (Fig. 3A). For example, Nt-acetylated Cog1, a subunit of the conserved oligomeric Golgi (COG) complex is targeted for degradation by another Ac/N-recognin, Not4 E3 ligase, rather than Doa10. Interestingly, the short-lived Cog1 becomes longer-lived upon co-overexpression of the binding partner proteins Cog2, Cog3, and Cog4 by shielding its Ac/N-degron within the COG complex (Shemorry et al., 2013). The crystal structure of the Hcn1 and Cut9 subunits of Schizosaccharomyces pombe APC/C E3 ligase suggests that Hcn1 escapes from the Ac/N-end rule pathway by placing its acetylated Nt-Met in the cavity of Cut9 (Zhang et al., 2010). Indeed, unmasked Hcn1 is degraded via its Ac/N-degron when it is heterologously expressed in S. cerevisiae. Similar to the stoichiometry-mediated degradation control of the COG complex, co-expression of Cut9 represses the degradation of $\mathrm{Hcn} 1$ by shielding its Ac/N-degron (Shemorry et al., 2013). Additionally, Nt-acetylated Ser of the H4 peptide or $\mathrm{Nt}$-acetylated Met of Dcn1 is specifically enclosed within the cavity of the double PHD1/2 finger DPF3b transcriptional protein or Ubc12 E3 enzyme, respectively (Scott et al., 2011; Zeng et al., 2010). It remains to be determined whether DPF3b and Ubc12 shield the Ac/N-degrons of $\mathrm{H} 4$ and Dcn 1 . The condition- ality of the Ac/N-degron is further demonstrated in human wildtype Rgs2, a regulator of G-protein signaling. Rgs2 bearing an $\mathrm{Ac} / \mathrm{N}$-degron is strongly stabilized by the co-overexpression of one of its binding partners, the $\mathrm{Gq}$ protein (Park et al., 2015).

The conditional nature of Ac/N-degrons provides a new paradigm for how protein levels are sensed and balanced with respect to their interacting proteins. The conditionality of $\mathrm{Ac} / \mathrm{N}$ degrons also holds true for other degrons, thus providing new insight into the regulation of protein quality and stoichiometric levels of individual proteins. For example, the steady-state levels of the decapping enzyme Dcp2 are modulated by competition between its degradation and assembly into decapping complexes, despite the apparent internal degrons of Dcp2 (Erickson et al., 2015). As another example, S. cerevisiae fatty acid synthase (FAS) complex subunits become short-lived in the absence of respective ligands. Interestingly, unassembled Fas2 is eliminated by the Ubr1-mediated degradation pathway, possibly via its internal degron(s), similar to subunit stoichiometric control by the Ac/N-end rule pathway (Scazzari et al., 2015). In addition, frequent aneuploidy in cancer cells and trisomy 21 in Down syndrome may perturb input subunit stoichiometries of protein complexes due to altered specific gene 
dosages and a subsequent increase in unassembled or misfolded proteins (Hwang et al., 2010b). Accordingly, intracellular proteolytic systems are likely to regulate the subunit stoichiometry of complexes by targeting aberrant or unassembled proteins for the maintenance of protein quality and homeostasis.

\section{THE AC/N-END RULE PATHWAY IN MAMMALS}

The Arg/ $\mathrm{N}$-end rule pathway is conserved across eukaryotic species, from fungi to mammals and plants, and has recently been identified in S. cerevisiae (Hwang et al., 2010b). We demonstrated the existence of the Ac/N-end rule pathway in mammals and identified wild-type MQ-Rgs2 (with Nt-Met-GIn), a regulator of G-protein signaling, as the first physiological substrate of the mammalian $\mathrm{Ac} / \mathrm{N}$-end rule pathway (Park et al., 2015) (Fig. 3B). Additionally, two hypertension-associated $2^{\text {nd }}$. position missense human mutants, ML-Rgs2 (with Nt-Met-Leu) and MR-Rgs2 (with Nt-Met-Arg), are physiological substrates of the human Ac/N-end rule pathway (Bodenstein et al., 2007; Park et al., 2015). Both ML-Rgs2 and MR-Rgs2 are significantly shorter-lived than MQ-Rgs2, partially explaining the association between these mutants and hypertension in humans; reduced Rgs2 levels upregulate vasoconstrictors and have a weaker inactivation effect on $\mathrm{Gq}$ proteins, leading to high blood pressure (Aksnes et al., 2015a; Bodenstein et al., 2007; Park et al., 2015) (Fig. 3B). The ER membrane-embedded human Teb4 (March6) E3 ligase, an ortholog of yeast Doa10, (Hassink et al., 2005) was identified as the first mammalian Ac/N-recognin. Teb4 targets wild-type MQ-Rgs2 and hypertensive ML-Rgs2 and MR-Rgs2 by directly recognizing their N-terminal acetyl groups (Park et al., 2015). While human MQ-Rgs2 and its mutant MR-Rgs2 are targeted for degradation solely by the Ac/Nend rule pathway, the other hypertension-associated (and the shortest-lived) ML-Rgs2 mutant is targeted by both the Ac/Nend rule pathway (as Nt-acetylated ML-Rgs2) and the Arg/Nend rule pathway (as Nt-unacetylated ML-Rgs2), consistent with the dual targeting mechanism of Met- $\Phi$-proteins by two branches of the $\mathrm{N}$-end rule pathways in yeast (see below). Consequently, the dual degradation of the hypertensive MLRgs2 strongly decreases ML-Rgs2 levels, leading to high blood pressure by promoting Gq-protein signaling (Aksnes et al., 2015a; Park et al., 2015) (Fig. 3B).

Out of $\sim 30$ RGS family proteins in humans, Nt-Cys of Rgs4, Rgs5, and Rgs16 are subject to oxidation, Nt-arginylation, and subsequent degradation by the Arg/N-end rule pathway (Gibbs, 2015; Hu et al., 2005; Lee et al., 2005; 2015). The identification of Rgs2 as an Ac/N-end rule substrate suggests that other RGS proteins, including Rgs1, Rgs6, and Rgs7, may also be substrates of either the $\mathrm{Ac} / \mathrm{N}$-end rule or $\mathrm{Arg} / \mathrm{N}$-end rule pathways depending on their Nt-sequence contexts and Ntacetylation states (Park et al., 2015).

Similar to Rgs2 variants in hypertension patients, $2^{\text {nd }}$-position mutations are observed in many proteins, particularly in cancer cell exomes (Kandoth et al., 2013). Some cancer-related proteins may become longer- or shorter-lived as a result of $2^{\text {nd }}$ position mutations, which cause their targeting to either the Arg/ $/ \mathrm{N}$-end rule pathway or the Ac/N-end rule pathway (Table 1 ) (Fig. 3C). For example, the tumor suppressor Dab2 (Disabled homolog 2), $80-90 \%$ of which is lost in ovarian and breast cancer cells (Bagadi et al., 2007), and ENSA ( $\alpha$-endosulfine), of which overexpression suppresses hepatic tumor growth (Chen et al., 2013), are expected to be short-lived due to their $2^{\text {nd }}$ position mutations in cancer cells. In contrast, Reg3A (regenerating islet-derived protein $3 \alpha$ ), which accelerates pancreatic cancer cell growth (Liu et al., 2013), may be long-lived due to its $2^{\text {nd }}$-position mutation. Accordingly, it is unclear whether particular $2^{\text {nd }}$-position mutations contribute to the development of extant malignant phenotypes by faster or delayed degradation of specific proteins (Table 1).

A handful of cellular proteins are shown to be putative substrates of the Ac/N-end rule pathway. For example, a short-lived endogenous $\mathrm{p} 21^{\mathrm{Cip} 1}$, a CDK inhibitor in mammalian cells, is acetylated at its $\mathrm{Nt}-\mathrm{Ser}$, indicating that the resulting Nt-acetyl Ser may control the half-life of $121^{\text {Cip } 1}$ (Lu and Hunter, 2010). In addition, C. elegans RHY-1, an ER acyltransferase-like protein, appears to promote the degradation of CYSL-1, a putative sulfhydrylase/cysteine synthase, potentially by increasing the $\mathrm{Nt}$-acetylation of CYSL-1 (Ma et al., 2012). Furthermore, Nt-Ala of $\mathrm{NaV1.5,} \alpha$ subunit of the cardiac voltage-gated sodium channel, is acetylated at the end of heart failure. The resulting

Table 1. Cancer-related proteins with mutations at position 2

\begin{tabular}{|c|c|c|c|}
\hline Cancer-related proteins & $\begin{array}{l}\text { Original } \\
\text { sequence }\end{array}$ & Mutations at position 2 & Carcinoma \\
\hline FARSB (Phe-tRNA ligase $\beta$ subunit) & MPTVSV... & MLTVSV... & Head/neck squamous cell \\
\hline POLR2C (RNA polymerase II subunit) & MPYANQ... & MLYANQ.... & Bladder urothelial \\
\hline elF1AX (eukaryotic translation initiation factor $1 \mathrm{~A}$ ) & MPKNKG... & MSKNKG... & Uterine corpus Endometrial \\
\hline Dab2 (disabled homolog 2) & MSNEVE... & MFNEVE... & Breast invasive \\
\hline ENSA (alpha-endosulfine) & MSQKQE... & MYQKQE... & Breast invasive \\
\hline HIST2H2AB (histone H2A type 2-B) & MSGRGK... & MLGRGK... & Head/neck squamous cell \\
\hline Rgs2 (regulator of G-protein signaling 2) & MQSAMF... & MLSAMF... & Breast invasive \\
\hline Cdk19 (cyclin-dependent kinase 19) & MDYDFK... & MYYDFK... & Kidney renal clear cell \\
\hline Reg3A (regenerating islet-derived protein 3- $\alpha$ ) & MLPPMA... & MPPPMA... & Lung adeno \\
\hline elF5 (eukaryotic translation initiation factor 5 ) & MSVNVN... & MPVNVN... & Lung squamous cell \\
\hline
\end{tabular}

* Similar to Rgs2 variants in hypertension patients, many cancer cell exomes encode cellular proteins with mutations at position 2 (Kandoth et al., 2013), which are likely to make cancer-related proteins shorter-lived or longer-lived by affecting two branches of the N-end rule pathways. $2^{\text {nd }}$-position mutations listed above have mutation assessor scores above 2.0, indicating significant impacts on protein function. All information about cancer-related mutations was acquired and analyzed from datasets of The Cancer Genome Atlas (https://tcga-data.nci.nih.gov/tcga). 
acetylated Nt-Ala of NaV1.5 is predicted to have an Ac/Ndegron, because its steady-state level is significantly lower in typical heart failure than in normal conditions (Beltran-Alvarez et al., 2014). However, additional studies are needed to prove that the Ac/N-end rule pathway mediates the degradation of p21 ${ }^{\mathrm{Cip} 1}$, CYSL-1, and NaV1.5.

The Ac/N-end rule pathway may alleviate ER stresses because Nt-acetylation prevents cellular protein targeting to the $\mathrm{ER}$, leading to the elimination of retained $\mathrm{Nt}$-acetylated proteins in the cytosol (Forte et al., 2011). Additionally, Teb4 may mediate the degradation of some previously identified substrates, such as the thyroid hormone-activating type 2 iodothyronine deiodinase (D2) (Zavacki et al., 2009), the cholesterol biosynthetic enzyme squalene monooxygenase (SM) (Foresti et al., 2013; Zelcer et al., 2014), and the salt export pump BSEP (Wang et al., 2008), at least in part via their acetylated Ntresidues before or after the targeting to the ER under some stress conditions.

\section{THE AC/N-END RULE PATHWAY IN PLANTS}

$\mathrm{Nt}$-acetylation is also an abundant modification in plant cells, which contain a unique chloroplast-localized Nt-acetylase, AtNaa70, as well as 6 Nt-acetylases, NatA-F (Dinh et al., 2015). Loss of the Nt-acetylases NatA, NatB, or NatC in plants results in lethal or pleiotropic deleterious phenotypes (Gibbs, 2015). Despite the presence of SUD2 (suppressor of dry2 defects 1) E3 ligase (Doblas et al., 2013), a sequelog of yeast Doa10 and human TEB4, the Ac/N-end rule pathway has not yet been established in plants. Interestingly, the plant immune receptor SNC1 (suppressor of nod-like protein receptor 1, constitutive 1) has an Ac/N-degron. The SNC1 contains two distinct Nt-variants starting with Met-Met-Asp and Met-Asp Nt-sequences, likely owing to alternative translation initiation; they are differentially regulated by NatA and NatB Nt-acetylases, respectively (Xu et al., 2015) (Fig. 3D). More interestingly, NatA acetylates the Met-Met-Asp Nterminus of SNC1 and triggers its degradation by creating an Ac/N-degron. In contrast, NatB antagonistically stabilizes SNC1 by acetylating the Met-Asp N-terminus. These results uncover the first $\mathrm{Ac} / \mathrm{N}$-degron in plants and show the dual roles of Ntacetylation as a destabilizer or a stabilizer for newly synthesized proteins to reach appropriate amounts in a timely manner within a cell (Gibbs, 2015; Xu et al., 2015) (Fig. 3D).

Many plastid precursor proteins are Nt-acetylated and accumulate outside of plastids in the absence of Toc159, a main receptor for photosynthetic proteins. Consequently, Ntacetylated plastid precursors are most likely to be eliminated by the Ac/ $\mathrm{N}$-end rule pathway to avoid the accumulation of unfolded proteins in the cytosol (Grimmer et al., 2014). Furthermore, populations of Nt-acetylated proteins are likely to be modulated in response to external stress in plants. For example, drought and abscisic acid-associated stresses drastically reduce Ntacetylated proteins through the depletion of NAA10 mRNA and a subsequent decrease in the Naa10 expression levels, leading to impaired growth and development (Linster et al., 2015). It is not clear whether the dramatic changes in Naa10 levels influence the degradation patterns of the global proteome by the Ac/N-end rule pathway.

\section{REGULATION OF THE AC/N-END RULE PATHWAY BY NT-ACETYLASES AND ACETYL-COA}

Despite the abundance and irreversibility of Nt-acetylation, the transcription levels of $\mathrm{Nt}$-acetylase subunits change significantly during development or under stress conditions (Graveley et al., 2011; Linster et al., 2015; Silva and Martinho, 2015). In addition, specific Nt-acetylases are modified by phosphorylation or acetylation for different cellular responses (Malen et al., 2009; Seo et al., 2010). Therefore, altered amounts or activities of specific Nt-acetylases are likely to affect protein expression patterns during development or stress conditions by changing the production of $\mathrm{Ac} / \mathrm{N}$-degrons. Intracellular levels of a key metabolic intermediate, acetyl-CoA, also change according to the metabolic states of cells, thus affecting gene expression, cell proliferation, cancer metabolism, autophagy, etc. (Pietrocola et al., 2015). Because acetyl-CoA acts as a cosubstrate for the reaction, its levels are also likely to affect the $\mathrm{Nt}$-acetylation of cellular proteins. For example, reduced acetylCoA levels decrease the acetylation of apoptosis effectors, thus linking metabolic conditions with cell death (Yi et al., 2011). The prevalence of $\mathrm{Ac} / \mathrm{N}$-degrons in a vast majority of proteins also suggests that changing acetyl-CoA levels may have effects on the global proteome by modulating the activities of $\mathrm{Nt}$ acetylases and $\mathrm{Ac} / \mathrm{N}$-end rule components.

\section{N-FORMYL DEGRON AND ITS RELEVANT N-END RULE PATHWAY IN BACTERIA}

The discovery of Ac/N-degrons led to the hypothesis that the transient Nt-formyl Met (fMet) of nascent proteins acts as an fMet-based N-degron owing to the similarity between acetyl and formyl groups on Nt-Met and their identical localization at $\mathrm{N}$ termini (Hwang et al., 2010b). The fMet residue occurs in nascent proteins of bacteria and eukaryotic organelles, such as mitochondria and chloroplasts. The inhibition or loss of deformylase activity decreases the levels of chloroplast D2 in Chlamydomonas reinhardtii (Giglione et al., 2003) as well as D2derived reporters and many high-molecular-weight proteins in $E$. coli by accelerating their degradation via the retained formyl group (Piatkov et al., 2015). The effects are also abrogated by mutations that prevent formylation. These and related findings strongly suggest that fMet acts as a new kind of $\mathrm{N}$-degron by a bacterial fMet/N-end rule pathway (Piatkov et al., 2015). The ATP-dependent protease FtsH may be a fMet/N-recognin that mediates the proteolysis of the $E$. coli membrane protein YfgM by targeting its fMet (Dohmen, 2015; Piatkov et al., 2015). The $\mathrm{fMet} / \mathrm{N}$-end rule pathway is also thought to be involved in protein quality control by the preferential and largely cotranslational degradation of Nt-formylated misfolded or unassembled proteins (Dohmen, 2015; Piatkov et al., 2015).

\section{CONCLUSION}

Most cellular proteins are Nt-acetylated, but the universal functions of this modification are largely unknown. The discovery of $\mathrm{Ac} / \mathrm{N}$-degrons and the $\mathrm{Ac} / \mathrm{N}$-end rule pathway represents a remarkable breakthrough in our understanding of the cellular functions of Nt-acetylation. Recent studies of the $\mathrm{Ac} / \mathrm{N}$-end rule pathway have unraveled the complementary crosstalk between two branches of the $\mathrm{N}$-end rule pathway, fMet/N-degrons in bacteria, and a wide range of cellular roles, including the control of protein quality and subunit stoichiometry, the regulation of blood pressure via G-protein signaling, and plant stress and immune responses. Nonetheless, the discovery of $\mathrm{Ac} / \mathrm{N}$ degrons and the $\mathrm{Ac} / \mathrm{N}$-end rule pathway is still the beginning of an entirely new and broad research field. Because Ac/Ndegrons are present in nearly all proteins and can be conditionally modulated, a detailed understanding of the $\mathrm{Ac} / \mathrm{N}$-end rule 
pathway will set the stage for new therapeutic approaches based on inhibitors or activators of MetAPs, specific Ntacetylases, and other components of the $\mathrm{Ac} / \mathrm{N}$-end rule pathway, including Ac/N-recognins (Hwang et al., 2010a; Lee et al., 2015; Park et al., 2015).

\section{ACKNOWLEDGMENTS}

We are grateful to the present and former members of the Hwang laboratory, particularly $\mathrm{N}$. Kha for his comments on the paper. This work was supported by grants from the National Research Foundation of the Korea government (MSIP) (NRF2012R1A4A1028200 and NRF-2013R1A1A2012529) and the BK21 Plus Program.

\section{REFERENCES}

Aksnes, H., Drazic, A., and Arnesen, T. (2015a). (Hyper)tension release by N-terminal acetylation. Trends Biochem. Sci. 40, 422424.

Aksnes, H., Hole, K., and Arnesen, T. (2015b). Molecular, cellular, and physiological significance of $\mathrm{N}$-terminal acetylation. Int. Rev. Cell Mol. Biol. 316, 267-305

Aksnes, H., Van Damme, P., Goris, M., Starheim, K.K., Marie, M., Stove, S.I., Hoel, C., Kalvik, T.V., Hole, K., Glomnes, N., et al. (2015c). An organellar nalpha-acetyltransferase, naa60, acetylates cytosolic $\mathrm{N}$ termini of transmembrane proteins and maintains Golgi integrity. Cell Rep. 10, 1362-1374.

Arnesen, T., Van Damme, P., Polevoda, B., Helsens, K., Evjenth, R., Colaert, N., Varhaug, J.E., Vandekerckhove, J., Lillehaug, J.R., Sherman, F., et al. (2009). Proteomics analyses reveal the evolutionary conservation and divergence of N-terminal acetyltransferases from yeast and humans. Proc. Natl. Acad. Sci. USA 106, 8157-8162.

Arnesen, T., Starheim, K.K., Van Damme, P., Evjenth, R., Dinh, H., Betts, M.J., Ryningen, A., Vandekerckhove, J., Gevaert, K., and Anderson, D. (2010). The chaperone-like protein HYPK acts together with NatA in cotranslational $\mathrm{N}$-terminal acetylation and prevention of Huntingtin aggregation. Mol. Cell. Biol. 30, 18981909.

Bachmair, A., Finley, D., and Varshavsky, A. (1986). In vivo half-life of a protein is a function of its amino-terminal residue. Science 234, 179-186.

Bagadi, S.A., Prasad, C.P., Srivastava, A., Prashad, R., Gupta, S.D., and Ralhan, R. (2007). Frequent loss of Dab2 protein and infrequent promoter hypermethylation in breast cancer. Breast Cancer Res. Treat. 104, 277-286.

Behnia, R., Panic, B., Whyte, J.R., and Munro, S. (2004). Targeting of the Arf-like GTPase Arl3p to the Golgi requires N-terminal acetylation and the membrane protein Sys1p. Nat. Cell Biol. 6, 405-413.

Beltran-Alvarez, P., Tarradas, A., Chiva, C., Perez-Serra, A., Batlle, M., Perez-Villa, F., Schulte, U., Sabido, E., Brugada, R., and Pagans, S. (2014). Identification of $\mathrm{N}$-terminal protein acetylation and arginine methylation of the voltage-gated sodium channel in end-stage heart failure human heart. J. Mol. Cell. Cardiol. 76, 126-129.

Bhattacharjee, A., Majumdar, U., Maity, D., Sarkar, T.S., Goswami, A.M., Sahoo, R., and Ghosh, S. (2009). In vivo protein tyrosine nitration in S. cerevisiae: identification of tyrosine-nitrated proteins in mitochondria. Biochem. Biophys. Res. Commun. 388, 612-617.

Bischof, S., Baerenfaller, K., Wildhaber, T., Troesch, R., Vidi, P.A., Roschitzki, B., Hirsch-Hoffmann, M., Hennig, L., Kessler, F., Gruissem, W., et al. (2011). Plastid proteome assembly without Toc159: photosynthetic protein import and accumulation of $\mathrm{N}$ acetylated plastid precursor proteins. Plant Cell 23, 3911-3928.

Bodenstein, J., Sunahara, R.K., and Neubig, R.R. (2007). Nterminal residues control proteasomal degradation of RGS2, RGS4, and RGS5 in human embryonic kidney 293 cells. Mol. Pharmacol. 71, 1040-1050.

Cha-Molstad, H., Sung, K.S., Hwang, J., Kim, K.A., Yu, J.E., Yoo, Y.D., Jang, J.M., Han, D.H., Molstad, M., Kim, J.G., et al. (2015). Amino-terminal arginylation targets endoplasmic reticulum chaperone BiP for autophagy through p62 binding. Nat. Cell Biol. 17, 917-929.

Chen, S., Vetro, J.A., and Chang, Y.H. (2002). The specificity in vivo of two distinct methionine aminopeptidases in Saccharomyces cerevisiae. Arch. Biochem. Biophys. 398, 87-93.

Chen, Y.L., Kuo, M.H., Lin, P.Y., Chuang, W.L., Hsu, C.C., Chu, P.Y Lee, C.H., Huang, T.H., Leu, Y.W., and Hsiao, S.H. (2013) ENSA expression correlates with attenuated tumor propagation in liver cancer. Biochem. Biophys. Res. Commun. 442, 56-61.

Ciechanover, A., and Ben-Saadon, R. (2004). N-terminal ubiquitination: more protein substrates join in. Trends Cell Biol. 14, 103106.

Ciechanover, A., and Kwon, Y.T. (2015). Degradation of misfolded proteins in neurodegenerative diseases: therapeutic targets and strategies. Exp. Mol. Med. 47, e147.

Dinh, T.V., Bienvenut, W.V., Linster, E., Feldman-Salit, A., Jung, V.A., Meinnel, T., Hell, R., Giglione, C., and Wirtz, M. (2015). Molecular identification and functional characterization of the first Nalpha-acetyltransferase in plastids by global acetylome profiling. Proteomics 15, 2426-2435.

Ditzel, M., Wilson, R., Tenev, T., Zachariou, A., Paul, A., Deas, E., and Meier, P. (2003). Degradation of DIAP1 by the $\mathrm{N}$-end rule pathway is essential for regulating apoptosis. Nat. Cell Biol. 5 , 467-473

Doblas, V.G., Amorim-Silva, V., Pose, D., Rosado, A., Esteban, A. Arro, M., Azevedo, H., Bombarely, A., Borsani, O., Valpuesta, V., et al. (2013). The SUD1 gene encodes a putative E3 ubiquitin ligase and is a positive regulator of 3-hydroxy-3-methylglutaryl coenzyme a reductase activity in Arabidopsis. Plant Cell 25, 728-743.

Dohmen, R.J. (2015). Starting with a degron: N-terminal formylmethionine of nascent bacterial proteins contributes to their proteolytic control. Microbia Cell 2, 356-359.

Dorfel, M.J., and Lyon, G.J. (2015). The biological functions of Naa10 - From amino-terminal acetylation to human disease Gene 567, 103-131.

Dougan, D.A., Micevski, D., and Truscott, K.N. (2012). The N-end rule pathway: from recognition by $\mathrm{N}$-recognins, to destruction by AAA+proteases. Biochim. Biophys. Acta 1823, 83-91.

Erickson, S.L., Corpuz, E.O., Maloy, J.P., Fillman, C., Webb, K. Bennett, E.J., and Lykke-Andersen, J. (2015). Competition between decapping complex formation and ubiquitin-mediated proteasomal degradation controls human Dcp2 decapping activity. Mol. Cell. Biol. 35, 2144-2153.

Esmailpour, T., Riazifar, H., Liu, L., Donkervoort, S., Huang, V.H., Madaan S Shoucri, B.M., Busch, A Wu, J, Towbin, A et al. (2014). A splice donor mutation in NAA10 results in the dysregulation of the retinoic acid signalling pathway and causes Lenz microphthalmia syndrome. J. Med. Genet. 51, 185-196.

Ferrandez-Ayela, A., Micol-Ponce, R., Sanchez-Garcia, A.B., Alonso-Peral, M.M., Micol, J.L., and Ponce, M.R. (2013). Mutation of an Arabidopsis NatB N-alpha-terminal acetylation complex component causes pleiotropic developmental defects. PLoS One 8, e80697.

Foresti, O., Ruggiano, A., Hannibal-Bach, H.K., Ejsing, C.S., and Carvalho, P. (2013). Sterol homeostasis requires regulated degradation of squalene monooxygenase by the ubiquitin ligase Doa10/Teb4. Elife 2, e00953.

Forte, G.M., Pool, M.R., and Stirling, C.J. (2011). N-terminal acetylation inhibits protein targeting to the endoplasmic reticulum. PLoS Biol. 9, e1001073.

Garrels, J.I., McLaughlin, C.S., Warner, J.R., Futcher, B., Latter, G.I. Kobayashi, R., Schwender, B., Volpe, T., Anderson, D.S., Mesquita-Fuentes, R., et al. (1997). Proteome studies of Saccharomyces cerevisiae: identification and characterization of abundant proteins. Electrophoresis 18, 1347-1360.

Gautschi, M., Just, S., Mun, A., Ross, S., Rucknagel, P., Dubaquie Y., Ehrenhofer-Murray, A., and Rospert, S. (2003). The yeast $\mathrm{N}$ (alpha)-acetyltransferase NatA is quantitatively anchored to the ribosome and interacts with nascent polypeptides. Mol. Cell. Biol. 23, 7403-7414.

Ghislain, M., Dohmen, R.J., Levy, F., and Varshavsky, A. (1996). Cdc48p interacts with Ufd3p, a WD repeat protein required for ubiquitin-mediated proteolysis in Saccharomyces cerevisiae. EMBO J. 15, 4884-4899.

Gibbs, D.J. (2015). Emerging functions for N-terminal protein acety- 
lation in plants. Trends Plant Sci. 20, 599-601.

Gibbs, D.J., Lee, S.C., Isa, N.M., Gramuglia, S., Fukao, T., Bassel, G.W., Correia, C.S., Corbineau, F., Theodoulou, F.L., BaileySerres, J., et al. (2011). Homeostatic response to hypoxia is regulated by the $\mathrm{N}$-end rule pathway in plants. Nature $479,415-$ 418.

Gibbs, D.J., Bacardit, J., Bachmair, A., and Holdsworth, M.J. (2014). The eukaryotic $\mathrm{N}$-end rule pathway: conserved mechanisms and diverse functions. Trends Cell Biol. 24, 603-611.

Giglione, C., Vallon, O., and Meinnel, T. (2003). Control of protein life-span by N-terminal methionine excision. EMBO J. 22, 13-23.

Giglione, C., Fieulaine, S., and Meinnel, T. (2015). N-terminal protein modifications: bringing back into play the ribosome. Biochimie 114, 134-146.

Graveley, B.R., Brooks, A.N., Carlson, J.W., Duff, M.O., Landolin, J.M., Yang, L., Artieri, C.G., van Baren, M.J., Boley, N., Booth, B.W., et al. (2011). The developmental transcriptome of Drosophila melanogaster. Nature 471, 473-479.

Grimmer, J., Rodiger, A., Hoehenwarter, W., Helm, S., and Baginsky, S. (2014). The RNA-binding protein RNP29 is an unusual Toc159 transport substrate. Front Plant Sci. 5, 258.

Hammerle, M., Bauer, J., Rose, M., Szallies, A., Thumm, M., Dusterhus, S., Mecke, D., Entian, K.D., and Wolf, D.H. (1998). Proteins of newly isolated mutants and the amino-terminal proline are essential for ubiquitin-proteasome-catalyzed catabolite degradation of fructose-1,6-bisphosphatase of Saccharomyces cerevisiae. J. Biol. Chem. 273, 25000-25005.

Hassink, G., Kikkert, M., van Voorden, S., Lee, S.J., Spaapen, R., van Laar, T., Coleman, C.S., Bartee, E., Fruh, K., Chau, V., et al. (2005). TEB4 is a C4HC3 RING finger-containing ubiquitin ligase of the endoplasmic reticulum. Biochem. J. 388, 647-655.

Helbig, A.O., Rosati, S., Pijnappel, P.W., Van Breukelen, B., Timmers, M.H., Mohammed, S., Slijper, M., and Heck, A.J. (2010). Perturbation of the yeast $\mathrm{N}$-acetyltransferase NatB induces elevation of protein phosphorylation levels. BMC Genomics 11, 685 .

Hershko, A., Heller, H., Eytan, E., Kaklij, G., and Rose, I.A. (1984). Role of the alpha-amino group of protein in ubiquitin-mediated protein breakdown. Proc. Natl. Acad. Sci. USA 81, 7021-7025

Holmes, W.M., Mannakee, B.K., Gutenkunst, R.N., and Serio, T.R. (2014). Loss of amino-terminal acetylation suppresses a prion phenotype by modulating global protein folding. Nat. Commun. 5 , 4383 .

Hu, R.G., Sheng, J., Qi, X., Xu, Z., Takahashi, T.T., and Varshavsky, A. (2005). The $\mathrm{N}$-end rule pathway as a nitric oxide sensor controlling the levels of multiple regulators. Nature 437, 981-986.

Hwang, C.S., Shemorry, A., Auerbach, D., and Varshavsky, A. (2010a). The $\mathrm{N}$-end rule pathway is mediated by a complex of the RING-type Ubr1 and HECT-type Ufd4 ubiquitin ligases. Nat. Cell Biol. 12, 1177-1185.

Hwang, C.S., Shemorry, A., and Varshavsky, A. (2010b). N-terminal acetylation of cellular proteins creates specific degradation signals. Science 327, 973-977.

Hwang, C.S., Sukalo, M., Batygin, O., Addor, M.C., Brunner, H., Aytes, A.P., Mayerle, J., Song, H.K., Varshavsky, A., and Zenker, M. (2011). Ubiquitin ligases of the $\mathrm{N}$-end rule pathway: assessment of mutations in UBR1 that cause the Johanson-Blizzard syndrome. PLoS One 6, e24925.

Jornvall, H. (1975). Acetylation of Protein N-terminal amino groups structural observations on alpha-amino acetylated proteins. J. Theoretic. Biol. 55, 1-12.

Kalvik, T.V., and Arnesen, T. (2013). Protein N-terminal acetyltransferases in cancer. Oncogene 32, 269-276.

Kandoth, C., McLellan, M.D., Vandin, F., Ye, K., Niu, B., Lu, C., Xie, M., Zhang, Q., McMichael, J.F., Wyczalkowski, M.A., et al. (2013). Mutational landscape and significance across 12 major cancer types. Nature 502, 333-339.

Khmelinskii, A., and Knop, M. (2014). Analysis of protein dynamics with tandem fluorescent protein timers. Methods Mol. Biol. 1174, 195-210.

Kim, J.M., and Hwang, C.S. (2014). Crosstalk between the Arg/Nend and $\mathrm{Ac} / \mathrm{N}$-end rule. Cell Cycle 13, 1366-1367.

Kim, I., Miller, C.R., Young, D.L., and Fields, S. (2013). Highthroughput analysis of in vivo protein stability. Mol. Cell Proteomics 12, 3370-3378.

Kim, H.K., Kim, R.R., Oh, J.H., Cho, H., Varshavsky, A., and Hwang,
C.S. (2014). The $\mathrm{N}$-terminal methionine of cellular proteins as a degradation signal. Cell 156, 158-169.

Kwon, Y.T., Kashina, A.S., and Varshavsky, A. (1999). Alternative splicing results in differential expression, activity, and localization of the two forms of arginyl-tRNA-protein transferase, a component of the N-end rule pathway. Mol. Cell. Biol. 19, 182-193.

Lee, M.J., Tasaki, T., Moroi, K., An, J.Y., Kimura, S., Davydov, I.V., and Kwon, Y.T. (2005). RGS4 and RGS5 are in vivo substrates of the N-end rule pathway. Proc. Natl. Acad. Sci. USA 102, 15030-15035.

Lee, K.E., Ahn, J.Y., Kim, J.M., and Hwang, C.S. (2014). Synthetic lethal screen of NAA20, a catalytic subunit gene of NatB Nterminal acetylase in Saccharomyces cerevisiae. J. Microbiol. 52 842-848.

Lee, J.H., Jiang, Y., Kwon, Y.T., and Lee, M.J. (2015). Pharmacological modulation of the N-End rule pathway and its therapeutic Implications. Trends Pharmacol. Sci. 36, 782-797.

Linster, E., Stephan, I., Bienvenut, W.V., Maple-Grodem, J., Myklebust, L.M., Huber, M., Reichelt, M., Sticht, C., Geir Moller, S., Meinnel, T., et al. (2015). Downregulation of N-terminal acetylation triggers ABA-mediated drought responses in Arabidopsis. Nat. Commun. 6, 7640.

Liu, C.M., Hsieh, C.L., He, Y.C., Lo, S.J., Liang, J.A., Hsieh, T.F., Josson, S., Chung, L.W., Hung, M.C., and Sung, S.Y. (2013). In vivo targeting of ADAM9 gene expression using lentivirusdelivered shRNA suppresses prostate cancer growth by regulating REG4 dependent cell cycle progression. PLoS One 8 , e53795.

Lu, Z., and Hunter, T. (2010). Ubiquitylation and proteasomal degradation of the p21(Cip1), p27(Kip1) and p57(Kip2) CDK inhibitors. Cell Cycle 9, 2342-2352.

Ma, D.K., Vozdek, R., Bhatla, N., and Horvitz, H.R. (2012). CYSL-1 interacts with the O2-sensing hydroxylase EGL-9 to promote $\mathrm{H} 2 \mathrm{~S}$-modulated hypoxia-induced behavioral plasticity in C. elegans. Neuron 73, 925-940.

Malen, H., Lillehaug, J.R., and Arnesen, T. (2009). The protein Nalpha-terminal acetyltransferase hNaa10p (hArd1) is phosphorylated in HEK293 cells. BMC Res Notes 2, 32.

Meinnel, T., Peynot, P., and Giglione, C. (2005). Processed Ntermini of mature proteins in higher eukaryotes and their major contribution to dynamic proteomics. Biochimie 87, 701-712.

Menssen, R., Schweiggert, J., Schreiner, J., Kusevic, D., Reuther, J., Braun, B., and Wolf, D.H. (2012). Exploring the topology of the Gid complex, the E3 ubiquitin ligase involved in cataboliteinduced degradation of gluconeogenic enzymes. J. Biol. Chem. $287,25602-25614$

Mogk, A., and Bukau, B. (2010). Cell biology. When the beginning marks the end. Science 327, 966-967.

Mullen, J.R., Kayne, P.S., Moerschell, R.P., Tsunasawa, S., Gribskov, M., Colavito-Shepanski, M., Grunstein, M., Sherman, F., and Sternglanz, R. (1989). Identification and characterization of genes and mutants for an $\mathrm{N}$-terminal acetyltransferase from yeast. EMBO J. 8, 2067-2075

Narita, K. (1958). Isolation of acetylpeptide from enzymic digests of TMV-protein. Biochimi. Biophys. Acta 28, 184-191.

Park, E.C., and Szostak, J.W. (1992). ARD1 and NAT1 proteins form a complex that has $\mathrm{N}$-terminal acetyltransferase activity. EMBO J. 11, 2087-2093

Park, S.E., Kim, J.M., Seok, O.H., Cho, H., Wadas, B., Kim, S.Y., Varshavsky, A., and Hwang, C.S. (2015). Control of mammalian $\mathrm{G}$ protein signaling by $\mathrm{N}$-terminal acetylation and the $\mathrm{N}$-end rule pathway. Science 347, 1249-1252.

Pena, M.M., Melo, S.P., Xing, Y.Y., White, K., Barbour, K.W., and Berger, F.G. (2009). The intrinsically disordered N-terminal domain of thymidylate synthase targets the enzyme to the ubiquitin-independent proteasomal degradation pathway. J. Biol. Chem. 284, 31597-31607.

Pesaresi, P., Gardner, N.A., Masiero, S., Dietzmann, A., Eichacker, L., Wickner, R., Salamini, F., and Leister, D. (2003). Cytoplasmic $\mathrm{N}$-terminal protein acetylation is required for efficient photosynthesis in Arabidopsis. Plant Cell 15, 1817-1832.

Pezza, J.A., Langseth, S.X., Raupp Yamamoto, R., Doris, S.M., Ulin, S.P., Salomon, A.R., and Serio, T.R. (2009). The NatA acetyltransferase couples Sup35 prion complexes to the $[\mathrm{PSI}+]$ phenotype. Mol. Biol. Cell 20, 1068-1080. 
Piatkov, K.I., Vu, T.M., Hwang, C.S., and Varshavsky, A. (2015). Formyl-methionine as a degradation signal at the $\mathrm{N}$-termini of bacterial proteins. Microbia Cell 2, 376-393.

Pietrocola, F., Galluzzi, L., Bravo-San Pedro, J.M., Madeo, F., and Kroemer, G. (2015). Acetyl coenzyme A: a central metabolite and second messenger. Cell Metab. 21, 805-821.

Polevoda, B., Norbeck, J., Takakura, H., Blomberg, A., and Sherman, F. (1999). Identification and specificities of $\mathrm{N}$-terminal acetyltransferases from Saccharomyces cerevisiae. EMBO J. 18, 6155-6168.

Polevoda, B., Hoskins, J., and Sherman, F. (2009). Properties of $\mathrm{Nat} 4$, an N(alpha)-acetyltransferase of Saccharomyces cerevisiae that modifies $\mathrm{N}$ termini of histones $\mathrm{H} 2 \mathrm{~A}$ and $\mathrm{H} 4$. Mol. Cell. Biol. 29, 2913-2924.

Ravid, T., and Hochstrasser, M. (2008). Diversity of degradation signals in the ubiquitin-proteasome system. Nat. Rev. Mol. Cell Biol. 9, 679-690.

Rope, A.F., Wang, K., Evjenth, R., Xing, J., Johnston, J.J., Swensen J.J., Johnson, W.E., Moore, B., Huff, C.D., Bird, L.M., et al. (2011). Using VAAST to identify an X-linked disorder resulting in lethality in male infants due to $\mathrm{N}$-terminal acetyltransferase deficiency. Am. J. Hum. Genet. 89, 28-43.

Sawant, S.V., Kiran, K., Singh, P.K., and Tuli, R. (2001). Sequence architecture downstream of the initiator codon enhances gene expression and protein stability in plants. Plant Physiol. 126, 1630-1636.

Scazzari, M., Amm, I., and Wolf, D.H. (2015). Quality control of a cytoplasmic protein complex: chaperone motors and the ubiquitin-proteasome system govern the fate of orphan fatty acid synthase subunit Fas2 of yeast. J. Biol. Chem. 290, 4677-4687.

Scott, D.C., Monda, J.K., Bennett, E.J., Harper, J.W., and Schulman, B.A. (2011). N-terminal acetylation acts as an avidity enhancer within an interconnected multiprotein complex. Science 334, 674-678.

Seo, J.H., Cha, J.H., Park, J.H., Jeong, C.H., Park, Z.Y., Lee, H.S., Oh, S.H., Kang, J.H., Suh, S.W., Kim, K.H., et al. (2010). Arrest defective 1 autoacetylation is a critical step in its ability to stimulate cancer cell proliferation. Cancer Res. 70, 4422-4432.

Setty, S.R., Strochlic, T.I., Tong, A.H., Boone, C., and Burd, C.G. (2004). Golgi targeting of ARF-like GTPase Arl3p requires its Nalpha-acetylation and the integral membrane protein Sys $1 p$. Nat. Cell Biol. 6, 414-419.

Shemorry, A., Hwang, C.S., and Varshavsky, A. (2013). Control of protein quality and stoichiometries by $\mathrm{N}$-terminal acetylation and the N-end rule pathway. Mol. Cell 50, 540-551.

Silva, R.D., and Martinho, R.G. (2015). Developmental roles of protein N-terminal acetylation. Proteomics 15, 2402-2409.

Sriram, S.M., Kim, B.Y., and Kwon, Y.T. (2011). The N-end rule pathway: emerging functions and molecular principles of substrate recognition. Nat. Rev. Mol. Cell Biol. 12, 735-747.

Starheim, K.K., Gevaert, K., and Arnesen, T. (2012). Protein Nterminal acetyltransferases: when the start matters. Trends Biochem. Sci. 37, 152-161.

Sundberg, T.B., Darricarrere, N., Cirone, P., Li, X., McDonald, L., Mei, X., Westlake, C.J., Slusarski, D.C., Beynon, R.J., and Crews, C.M. (2011). Disruption of Wnt planar cell polarity signaling by aberrant accumulation of the MetAP-2 substrate Rab37. Chem. Biol. 18, 1300-1311.

Swanson, R., Locher, M., and Hochstrasser, M. (2001). A conserved ubiquitin ligase of the nuclear envelope/endoplasmic reticulum that functions in both ER-associated and Matalpha2 repressor degradation. Genes Dev. 15, 2660-2674

Tasaki, T., Sriram, S.M., Park, K.S., and Kwon, Y.T. (2012). The Nend rule pathway. Ann. Rev. Biochem. 81, 261-289.

Van Damme, P., Hole, K., Pimenta-Marques, A., Helsens, K., Vandekerckhove, J., Martinho, R.G., Gevaert, K., and Arnesen, T.
(2011). NatF contributes to an evolutionary shift in protein Nterminal acetylation and is important for normal chromosome segregation. PLoS Genet. 7, e1002169.

Van Damme, P., Lasa, M., Polevoda, B., Gazquez, C., EloseguiArtola, A., Kim, D.S., De Juan-Pardo, E., Demeyer, K., Hole, K. Larrea, E., et al. (2012). N-terminal acetylome analyses and functional insights of the $\mathrm{N}$-terminal acetyltransferase NatB. Proc. Natl. Acad. Sci. USA 109, 12449-12454.

Varshavsky, A. (2011). The $\mathrm{N}$-end rule pathway and regulation by proteolysis. Protein Sci. 20, 1298-1345.

Wang, L., Dong, H., Soroka, C.J., Wei, N., Boyer, J.L., and Hochstrasser, M. (2008). Degradation of the bile salt export pump at endoplasmic reticulum in progressive familial intrahepatic cholestasis type II. Hepatology 48, 1558-1569.

Weits, D.A., Giuntoli, B., Kosmacz, M., Parlanti, S., Hubberten, H.M., Riegler, H., Hoefgen, R., Perata, P., van Dongen, J.T., and Licausi, F. (2014). Plant cysteine oxidases control the oxygendependent branch of the $\mathrm{N}$-end-rule pathway. Nat. Commun. 5, 3425 .

Xu, Z., Payoe, R., and Fahlman, R.P. (2012). The C-terminal proteolytic fragment of the breast cancer susceptibility type 1 protein (BRCA1) is degraded by the $\mathrm{N}$-end rule pathway. J. Biol. Chem. 287, 7495-7502.

Xu, F., Huang, Y., Li, L., Gannon, P., Linster, E., Huber, M., Kapos, P., Bienvenut, W., Polevoda, B., Meinnel, T., et al. (2015). Two $\mathrm{N}$-terminal acetyltransferases antagonistically regulate the stability of a nod-like receptor in Arabidopsis. Plant Cell 27, 15471562.

Yamano, K., and Youle, R.J. (2013). PINK1 is degraded through the $\mathrm{N}$-end rule pathway. Autophagy 9, 1758-1769.

Yi, C.H., Pan, H., Seebacher, J., Jang, I.H., Hyberts, S.G., Heffron, G.J., Vander Heiden, M.G., Yang, R., Li, F., Locasale, J.W., et al. (2011). Metabolic regulation of protein $\mathrm{N}$-alpha-acetylation by Bcl-xL promotes cell survival. Cell 146, 607-620.

Zattas, D., and Hochstrasser, M. (2015). Ubiquitin-dependent protein degradation at the yeast endoplasmic reticulum and nuclear envelope. Crit. Rev. Biochem. Mol. Biol. 50, 1-17.

Zattas, D., Adle, D.J., Rubenstein, E.M., and Hochstrasser, M (2013). N-terminal acetylation of the yeast Derlin Der1 is essential for Hrd1 ubiquitin-ligase activity toward luminal ER substrates. Mol. Biol. Cell 24, 890-900.

Zavacki, A.M., Arrojo, E.D.R., Freitas, B.C., Chung, M., Harney, J.W., Egri, P., Wittmann, G., Fekete, C., Gereben, B., and Bianco, A.C. (2009). The E3 ubiquitin ligase TEB4 mediates degradation of type 2 iodothyronine deiodinase. Mol. Cell. Biol. 29, 5339-5347.

Zelcer, N., Sharpe, L.J., Loregger, A., Kristiana, I., Cook, E.C., Phan L., Stevenson, J., and Brown, A.J. (2014). The E3 ubiquitin ligase MARCH6 degrades squalene monooxygenase and affects 3-hydroxy-3-methyl-glutaryl coenzyme A reductase and the cholesterol synthesis pathway. Mol. Cell. Biol. 34, 1262-1270.

Zeng, L., Zhang, Q., Li, S., Plotnikov, A.N., Walsh, M.J., and Zhou, M.M. (2010). Mechanism and regulation of acetylated histone binding by the tandem PHD finger of DPF3b. Nature 466, 258262.

Zenker, M., Mayerle, J., Lerch, M.M., Tagariello, A., Zerres, K., Durie P.R., Beier, M., Hulskamp, G., Guzman, C., Rehder, H., et al. (2005). Deficiency of UBR1, a ubiquitin ligase of the $\mathrm{N}$-end rule pathway, causes pancreatic dysfunction, malformations and mental retardation (Johanson-Blizzard syndrome). Nat. Genet. $37,1345-1350$

Zhang, Z., Kulkarni, K., Hanrahan, S.J., Thompson, A.J., and Barford, D. (2010). The APC/C subunit Cdc16/Cut9 is a contiguous tetratricopeptide repeat superhelix with a homo-dimer interface similar to Cdc27. EMBO J. 29, 3733-3744. 